\title{
STAFF. DISCURSOS Y PRODUCCIÓN DE VIVIENDA EN LA ARGENTINA DESARROLLISTA
}

Lucas Longoni 


\section{LUCAS LONGONI}

Magister en Historia y Cultura de la Arquitectura y la Ciudad, Universidad Torcuato Di Tella (Argentina). Licenciado en Ciencias de la Comunicación y Arquitecto, Universidad de Buenos Aires (Argentina). Investigador asistente Instituto de Arte Americano y Docente, Facultad de Arquitectura, Diseño y Urbanismo, Universidad de Buenos Aires (Argentina).

FECHA DE RECEPCIÓN: 21 de junio de 2018

FECHA DE ACEPTACIÓN: 8 de julio de 2018.

REGISTRO BIBLIOGRÁFICO: Longoni, L. (2017). Staff. Discursos y producción de vivienda en la Argentina desarrollista. Anales de Investigación en Arquitectura, 7, 7-22. 


\section{RESUMEN}

A mediados de los años sesenta, el problema del acceso a la vivienda en la Argentina fue canalizado a través de distintas iniciativas estatales dentro del pensamiento desarrollista, favoreciendo el agrupamiento entre profesionales autónomos como así también la concentración de estudios ligados a empresas constructoras. Las nuevas condiciones diversificaron las respuestas del profesional a los encargos recibidos desde el estado.

En ese contexto, el surgimiento del estudio STAFF (Goldemberg, Bielus y Wainstein Krasuk), que resultará el más prolífico del periodo en producción de vivienda social, posicionó, desde su adhesión a la sociología urbana, el discurso teórico de las prácticas sociales y los aspectos motivacionales de los destinatarios como matriz de elaboración proyectual, relegando a un último plano el diseño urbano. no obstante, una aproximación a la obra de la oficina revela patrones formales que invariablemente se replican, contradiciendo sus proposiciones discursivas.

Palabras clave: Vivienda, STAFF, profesional, estado, desarrollismo.

\section{ABSTRACT}

In the mid-sixties, the problem of access to housing in Argentina was channeled through various state initiatives, favoring the grouping of autonomous professionals as well as the concentration of professional studios linked to construction companies. The new conditions diversified the responses of the professional to the orders received from the State.

In this context, the emergence of the STAFF studio (Goldemberg, Bielus and Wainstein Krasuk), which will be the most prolific of the period in terms of social housing, positioned, from its adherence to urban sociology, the theoretical discourse of social practices and motivational aspects of the addressees as a matrix of project design, relegating urban design to the last level. However, an approach to STAFF's work reveals formal patterns that invariably replicate, contradicting their discursive propositions.

Keywords: Towards modern architecture, Le Corbusier, Julius Shulman, Ville Savoye, Case Study Houses, architecture photography, composition of photographs. 


\section{DESARROLLISMO Y VIVIENDA}

El Ilamado "problema de la vivienda" fue canalizado, durante los años sesenta en la Argentina, a través de distintas iniciativas estatales encuadradas dentro del pensamiento desarrollista ${ }^{1}$. En ese periodo de creciente densidad política, signado por la revisión de los cánones del movimiento moderno, fueron promovidos diversos planes y programas que direccionaron el camino de la disciplina arquitectónica hacia el campo de los proyectos urbanos y la vivienda de escala masiva, marcando distancias significativas con las producciones anteriores. En efecto, si durante el Estado benefactor de los dos primeros gobiernos peronistas (1946-1955), la planificación de los conjuntos de vivienda había sido articulada por técnicos dentro de las oficinas gubernamentales, la promoción de llamados a concursos durante el desarrollismo bajo la modalidad de "proyecto y precio"2 provocó un desplazamiento en el ámbito disciplinar, favoreciendo la vinculación y el agrupamiento entre profesionales autónomos, como así también la concentración de estudios de cierta estructura ligados a empresas constructoras.

\footnotetext{
1 Sobre el pensamiento teórico del desarrollismo, ver CARDOSO, F., \& FALETTO, E. (2005) Dependencia y Desarrollo en América Latina. Buenos Aires, Siglo XXI Editores.

2 Sobre la modalidad de los concurso de "proyecto y precio" durante los años sesenta, ver SCHERE, R. (2006). Concursos 1825-2006. Buenos Aires: Sociedad Central de Arquitectos.
}

El impulso modernizador del desarrollismo apuntaba a una estrategia dual: la incorporación de tecnologías que diversifiquen la producción, como así también la articulación de inversiones desde el Estado que fomenten la infraestructura requerida por tal diversificación (Cardoso, Faletto; 1977: 5). En ese sentido, las administraciones de Arturo Frondizi (19581962) y Arturo Illia (1963-1966) elaboraron diferentes políticas de promoción de vivienda masiva y apoyo al crédito, materializadas luego durante las dictaduras de Juan Carlos Onganía (1966-1970), Roberto Levingston (1970-1971) y Alejandro Lanusse (1971-1973). En 1961 el gobierno de Frondizi creó el Consejo Nacional de Desarrollo $(C O N A D E)^{3}$, organismo dependiente del poder ejecutivo cuyo objetivo era fijar planes intermedios, y ese mismo año gestionó el Fondo Federal para la Vivienda ${ }^{4}$, dirigido por el Banco Central y el Consejo Federal para la Vivienda ${ }^{5}$, designados para integrar las políticas y planes nacionales junto a los provinciales como así también para movilizar el crédito a través del sistema de "ahorro y préstamo". En 1962 el Banco Interamericano de Desarrollo le otorgó un préstamo al país para implementar el Plan Federal de Vivienda formulado por la CONADE, centralizando su ejecución en el Banco Hipotecario Nacional (BHN), iniciado recién dos años más tarde durante el gobierno de Illia. Posteriormente se aprobó el Plan de

\footnotetext{
3 Decreto 7.200/61 del 23 de agosto de 1961.

4 Decreto 396/61 del 13 de enero de 1961.

5 Decreto 6.122/61 del 21 de julio de 1961.
} 
Erradicación de Villas de Emergencia (PEVE) que denunciaba la problemática de los asentamientos precarios y fijaba normas para la construcción de nuevas viviendas. No obstante, tal derrotero de instancias burocráticas no iba a traducirse en producciones efectivas hasta 1967, cuando bajo el gobierno de Onganía se dictó el Plan de Construcción de Viviendas para Erradicación de Villas en Capital Federal y Gran Buenos Aires ${ }^{7}$ y luego el Plan VEA (Viviendas Económicas Argentinas).

\section{STAFF. PROFESIONALES Y DISCIPLINAS EN LOS SESENTA}

Las nuevas condiciones emanciparon $y$ diversificaron las respuestas del profesional a las encomiendas provenientes desde los distintos departamentos de gobierno. Emergieron entonces ciertas perspectivas que, desde su adhesión a la sociología urbana y a enfoques interdisciplinarios, promovían la participación del usuario conformando el proyecto en función de sus demandas, relegando a un plano de menor valía las resultantes estéticas. En esa dirección surgió el estudio STAFF en 1964, liderado por Jorge Goldemberg e integrado por Olga Wainstein-Krasuk y Angela Teresa Bielus. Goldemberg, además de arquitecto, era un reconocido sociólogo, y había integrado durante los años cincuenta el pionero grupo OAM (Organización de Arquitectura Moderna) junto a

6 Ley 16.601/64 del 24 de noviembre de 1964.

7 Decreto ley 17.605/67 del 29 de diciembre de 1967.
Horacio Baliero, Carmen Córdova, Juan Manuel Borthagaray y Francisco Bullrich, entre otros. Para principios de los setenta, la oficina habría ya obtenido más de cuarenta premios en concursos de arquitectura y urbanismo, mayoritariamente sobre vivienda y bajo los lineamientos de un Estado comitente. Esta prolífica producción, mediada por la finalidad social, se motorizó mediante el trabajo conjunto de equipos de profesionales provenientes de distintas disciplinas -sociología, economía, trabajo social- en detrimento de una "arquitectura de autor", reposicionando el rol del arquitecto como un actor técnico-político alejado de esteticismos (Liernur, Aliata; 2004: 72). En efecto, el discurso teórico de STAFF pregonaría la idea que "la forma de la arquitectura sigue la práctica social”, en sintonía con ciertas conceptualizaciones circulantes en la discusión internacional de posguerra, para lo cual la lógica proyectual de sus conjuntos de vivienda debía necesariamente prever la alternativa de crecimiento y flexibilidad, a tono con las demandas de los usuarios.

No obstante, una aproximación inicial a la obra de STAFF revela patrones de diseño que invariablemente se replican tramas, tiras, racimos- en diversos proyectos urbanos, manifestando en los hechos mayor relevancia a la exploración y determinación formal. Esas figuras, que con variaciones la oficina reprodujo en los conjuntos Morón, Ciudadela, La Matanza, Florencio Varela y Soldati, entre otros de la periferia de Buenos Aires, se asemejan a la 
configuración de una ciudad alternativa como reelaboración de ciertas imágenes del ámbito disciplinar global, extendida en el territorio a partir de bloques de media densidad, que anticiparía un antagonismo entre los discursos teóricos y las producciones del estudio.

\section{APUNTES SOBRE LA CIUDAD EXTENSA}

Según explica Roberto Fernández, durante los años sesenta "se consolidaba la idea de desarrollar los conjuntos de la llamada 'vivienda de interés social' en base a realizaciones de más tamaño, menor densidad (lo que equivalía a disponer de predios de mayores superficies) y, por la alta incidencia de los costos del suelo, implantaciones más periféricas" (Fernández; 1996: 58), prevaleciendo la sintonía entre los departamentos públicos, los estudios profesionales y las compañías constructoras para desarrollar los grandes emprendimientos que por entonces emergían en las periferias de las ciudades europeas. Las soluciones adoptadas pretendían traducir en la expresión de una "megaforma" las nuevas demandas de mayor complejidad y variedad de los futuros destinatarios. Como ha apuntado Ana María Rigotti, "el cambio de escala que prometía hacer viable la síntesis de Arquitectura y Urbanismo, auguraba también la posibilidad de conciliar la permanencia de lo edilicio con la mutabilidad de las prácticas sociales" (Rigotti; 2013: 168).

En ese sentido, el modelo de "ciudad extensa" estaba asociado a ciertas ideas urbanas que el Team X proclamaba a fines de la década del cincuenta. En primer lugar, como reelaboración de teorías sociales basadas en el concepto de 'comunidad' (Gemeinschaft) y en la psicología de la percepción, nociones que usualmente se traducían en las metáforas del 'árbol' y el 'umbral' formuladas por Shadrac Woods, Alison y Peter Smithson y Aldo Van Eyck. Por otro lado, como referencia a la "teoría de los sistemas", que aplicaba el principio de la autorregulación de las máquinas a la sociedad, y de allí a todos los conjuntos organizados (Colquhoun; 2005: 220), perspectiva vinculada a la emergencia de las tecno-utopías de posguerra.

Estas configuraciones que se asociaban a la producción de una ciudad extensa y de predominio horizontal, implementadas en diversos proyectos de STAFF, habían sido apuntadas en los patrones elaborados por Fumihiko Maki en Investigations in Collective Form, obra publicada en 1964. El análisis de Maki intenta desentrañar el desarrollo histórico y los principios estructurales de la "forma colectiva" como representación y lógica de la agrupación de edificios y sus posibles implicancias en el urban design como generadores de segmentos urbanos. De sus investigaciones surge una clasificación de tres categorías, entre las cuales la "megaestructura" como forma urbana propone un gran marco contenedor de diversas funciones. En el pensamiento de Maki, por otra parte, no se disimulan las referencias a la teoría de sistemas: 
The ideal is a kind of master form which can move into ever new states of equilibrium and yet mantain visual consistency and a sense of continuing order in the long run. This suggests that the megaestructure which is composed of several independent systems that can expand or contract with the least disturbance to others would be more preferable to the one of a rigid hierarchical system

(Maki; 1964: 12).

De esta construcción teórica sobre las megaestructuras se desprenderán las estructuras ilimitadas como una potencial operación proyectual, las cuales en función de su carácter aislado y en oposición a la ciudad tradicional, volvieron a poner en discusión el diseño de la totalidad, cuestionando los parámetros de finitud (Aliata, 2013:53). En esa dirección, los proyectos urbanos y "megaconjuntos" habitacionales de los años sesenta necesariamente debían contemplar la posibilidad de crecimiento y flexibilidad de las unidades espaciales del conjunto, según las potenciales necesidades de los usuarios.

Asimismo, la idea de "ciudad extensa" es compatible con la conceptualización que Alison Smithson formulara en la edición de septiembre de 1974 de Architectural Design sobre los mat-building ${ }^{8}$, noción que había sido introducida en el último encuentro del Team
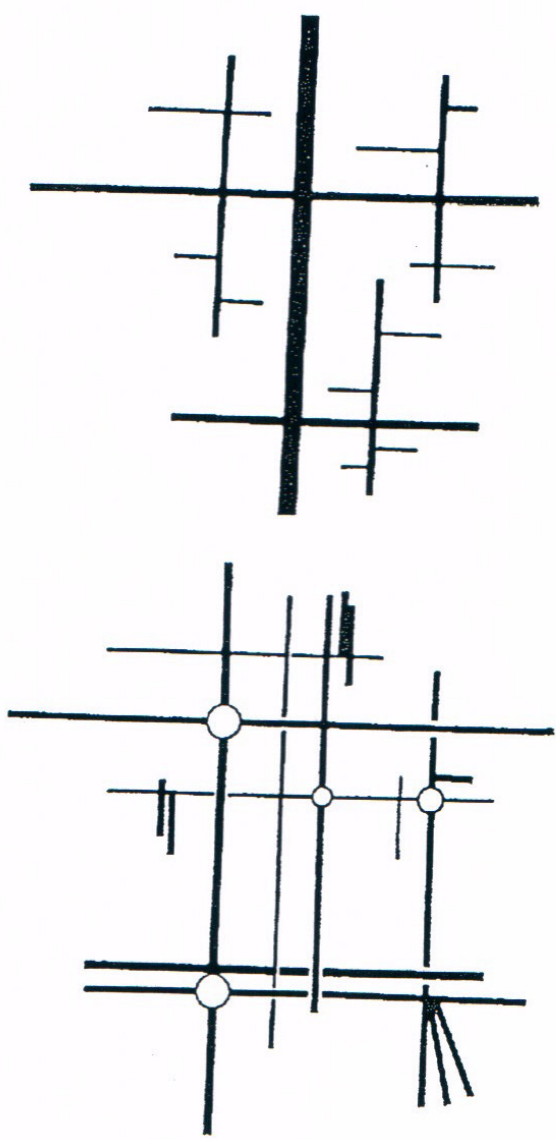

Figura 1

Dos tipos de "megaformas" según Maki. A la izquierda, la "megaforma jerárquica", a la derecha, la "megaforma ilimitada".

8 Ver SMITHSON, A. (1974). How to recognized and read Mat Building. Architectural Design, (9) set., 573590 . 


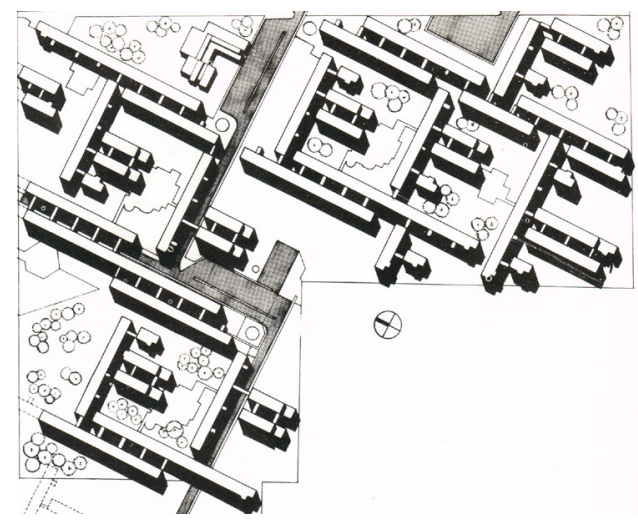

Figura 2.

STAFF. Proyecto urbano Morón. Planta de conjunto.
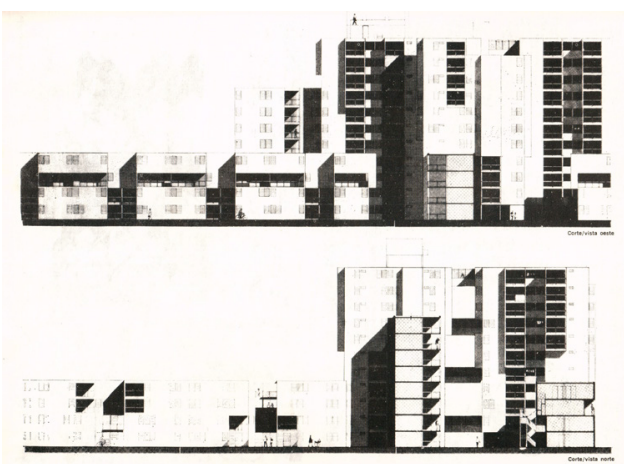

Figura 3

STAFF. Proyecto urbano Ciudadela. Cortes vistas de sistemas altos y bajos.
X en Berlín en 1973, acuñando allí el término "mat" como metáfora de un entramado o tejido textil que estructuraría los proyectos en su extensión horizontal sobre el territorio. Como analiza Colquhoun, el desarrollo del modelo apuntaba a acercar la relación cambiante y compleja entre la forma urbana y los procesos de sociabilización comunitarios: "Según los Smithson, la infraestructura debería hacer algo más que facilitar la formación espontánea de la comunidad; era preciso dar 'coherencia' a la estructura urbana [...] En ese aspecto, los Smithson parecían reconocer que existía una brecha entre las relaciones humanas espontáneas y su representación formal" (Colquhoun; 2005: 219).

\section{SOBRE DISCURSOS Y PROYECTOS EN STAFF}

Marina Waisman ha destacado, en la edición de la revista Summa dedicada al estudio en 1972, el acento de la actividad de STAFF en la vivienda de interés social soportada por una "infraestructura" de ideas y conceptos que subyace a cada proyecto y que Goldemberg construyó en susestudios de diversas disciplinas, como la sociología y el urbanismo, conformando una base ideológica que trascendiera el saber arquitectónico (Waisman, 1972: 4). Las estrategias proyectuales de la oficina estaban mediadas por la integración de principios sociológicos, urbanos y tecnológicos, que STAFF resumía en un plan de tres etapas. En primer lugar, era preciso estudiar con rigor científico 
y mediante un enfoque interdisciplinario las motivaciones habitacionales de los destinatarios, para dar una explicación inicial de la concepción del hábitat. En segundo término, la definición de ese "espacio social" debía reconocerse en un "espacio territorial", es decir, en la traducción del campo abstracto social al campo físico, a través de un efectivo planeamiento. Finalmente, el desarrollo de las instancias teóricas anteriores se sintetizaba en la escala menor, el diseño urbano resultante, tal como el propio Goldemberg manifestaba:

En el momento de realizar el proyecto, estos principios se fueron imprimiendo 0 introyectando dolorosamente en nosotros, pues hasta ese momento el diseño urbano parecía un problema simplemente geométrico. Era cuestión de aplicar los conocimientos interdisciplinarios para conformar una ‘imagen' nueva del diseño (Goldemberg; 1972: 10).

Sin embargo, los análisis preliminares para dilucidarel hábitatsocialen los distintos procesos proyectuales del estudio irremediablemente confluían en la determinación del modelo de "ciudad extensa" como solución. En efecto, las similitudes en los planteos urbanos empleados por STAFF en distintas convocatorias de los concursos PEVE suponen la utilización de la "trama" como un patrón formal pasible de ser replicado en distintos contextos, abriendo un interrogante sobre la viabilidad de las consideraciones sociológicas previas en cada

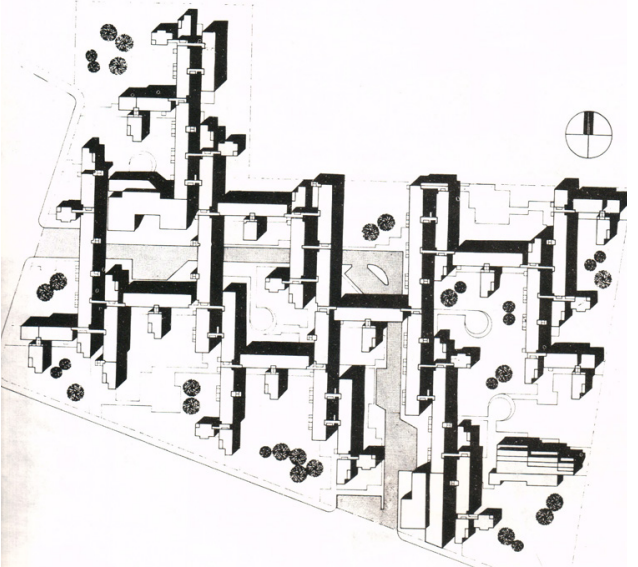

Figura 4.

STAFF. Proyecto urbano La Matanza. Planta de conjunto.

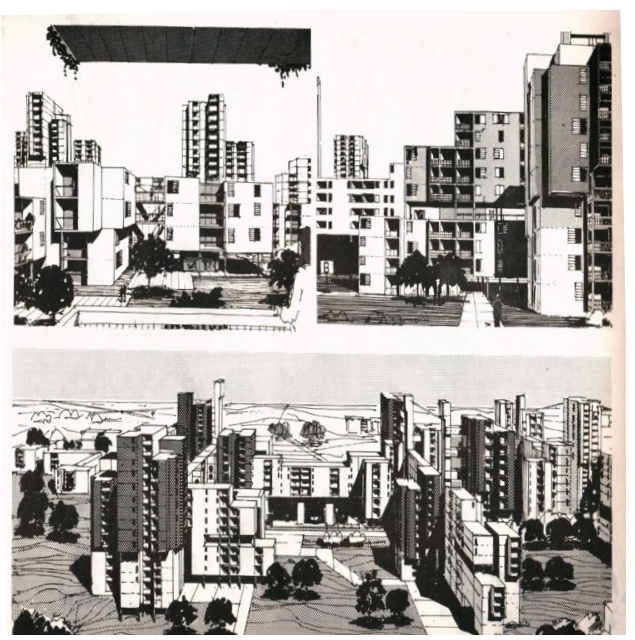

Figura 5.

STAFF. Proyecto urbano Soldati. Perspectivas. 


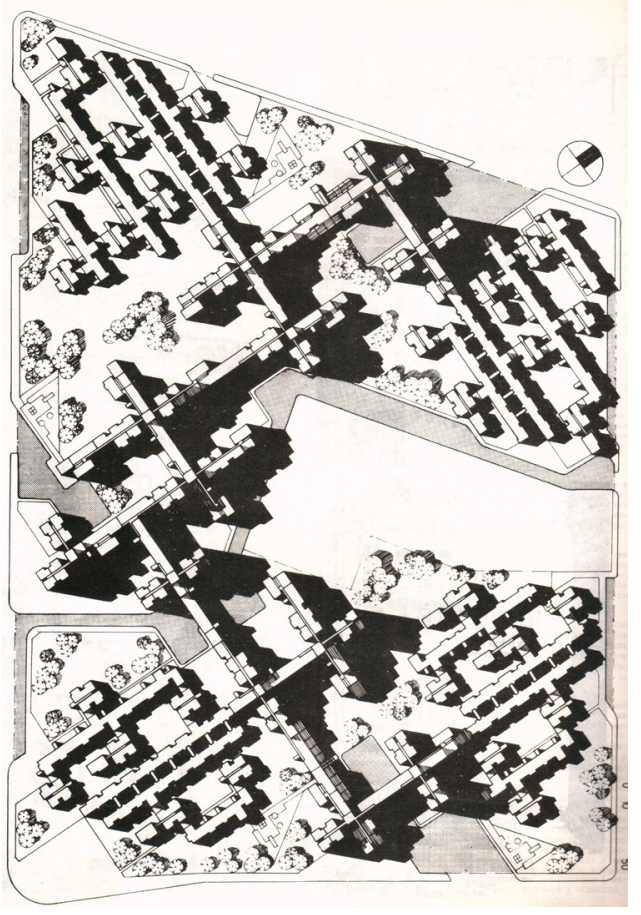

Figura 6.

STAFF. Proyecto urbano Soldati. Planta de conjunto. caso. Aquellas alegorías textiles traducidas de los planteos que circulaban en el ámbito europeo se presentaban como variantes de una misma imagen en presunto desarrollo, indeterminada. Se pretendía, en sintonía con lo expresado por Maki y los Smithson, generar un modelo complejo y crecedero que resuelva el par "forma urbana - hábitat social". La idea de "trama" en STAFF se conformaba entonces por bloques en tiras bajas, que sin intersectarse se articulaban ortogonalmente con otros conformando espacios internos, definidos como "áreas comunales" según la oficina. Esa lógica proyectual debía suponer ramificaciones flexibles de aquellos elementos, que posibilitaran un proceso de crecimiento $y$ extensión espacial ilimitados, desestimando así los bordes, en función de las renovadas demandas de los usuarios y la comunidad.

La periferia de la ciudad de Buenos Aires fue el territorio donde STAFF experimentó distintas producciones de aquella "ciudad extensa", en línea con los programas del desarrollismo. Por la vertiginosa y variada convocatoria de concursos, el PEVE resultó la instancia oportuna, "un caso de aplicación de lo que denominamos "nuestras ideas' de diseño urbano" (Goldemberg; 1972: 12). En esa dirección, en 1971 STAFF finalizaba la construcción del conjunto Morón, producto de los concursos números 11, 12 y 13 del "Programa de alojamiento definitivo" del PEVE, coordinado por la Secretaría de Vivienda de la Nación y operado por el BHN. El emprendimiento fue emplazado en el distrito de 
Haedo y destinado a alojar a 4.512 habitantes, conformado por tres grandes subconjuntos, "tramas" o “áreas comunales", diseñadas a partir de la disposición ortogonal de bloques horizontales de cuatro niveles de altura. EI conjunto se disgregaba de la ciudad mediante la articulación de esas figuras enlazadas por una calle vehicular interna, que rotadas en relación al perímetro del terreno negaban la condición de borde oponiéndose al damero tradicional, promoviendo nuevas alternativas para el habitar y la sociabilización barrial a partir del énfasis en los espacios abiertos interiores.

En el mismo año STAFF proyectó, en dos etapas, el conjunto habitacional "Ciudadela" o "Barrio Ejército de los Andes", cercano a la urbanización anterior. En este caso, la inclusión de torres junto a los bloques bajos mantuvo el patrón concebido a través de la "trama urbana", esta vez desglosado en dos sistemas de agrupamiento de viviendas, "altos" y "bajos", enlazados también por una calle principal interna de la cual se desprendían otros conectores. El objetivo de "recrear un microclima urbano" (Goldemberg; 1972: 84) variado y complejo posibilitó la inserción de torres en el entramado urbano sin que se desfigurara la imagen del conjunto, el cual incluyó, en una escala creciente, equipamiento cívico, escuela y locales comerciales. La novedad del "sistema alto" se materializó a través de la agrupación de tres torres con un único núcleo vertical, que el estudio llamó “nudos”, del cual se desprendían en las cuatro direcciones cardinales, las tiras bajas que conformaban el "sistema bajo".

La construcción teórica de STAFF fue también adecuada en el proyecto urbano de La Matanza (1971), donde la oficina había planteado el condicionamiento de su propuesta "a la doctrina urbanística aplicada al caso" (Goldemberg; 1972: 76). El sistema se generaba por el emplazamiento en sentido norte-sur de tiras bajas enfrentadas de a dos, conectadas entre sí por puentes y que encerraban calles peatonales. Bloques de menor longitud, en dirección esteoeste, trababan el conjunto conformando grandes patios interiores. La fidelidad a una impronta categórica como modelo de sus desarrollos en vivienda era suscripta en la memoria del proyecto: "el conjunto así definido, se estructura como un todo continuo, fuerte como imagen y claro como funcionamiento, en respuesta a aquellas premisas a que hacíamos mención en anteriores proyectos" (Goldemberg; 1972: 76).

Asimismo, la construcción de un "megaconjunto" para 16.000 habitantes en Villa Soldati (1971), proyectada por STAFF en extensas áreas no consolidadas del sudoeste la ciudad de Buenos Aires, implicó la necesidad de una sistematización precisa tanto en relación a las técnicas constructivas como a la configuración del amplio espacio urbano. También se promovió aquí un par que oponía un sistema de viviendas en altura con otro de tiras bajas en forma de "U", las cuales delimitaban diversos patios internos. Asimismo, las torres 


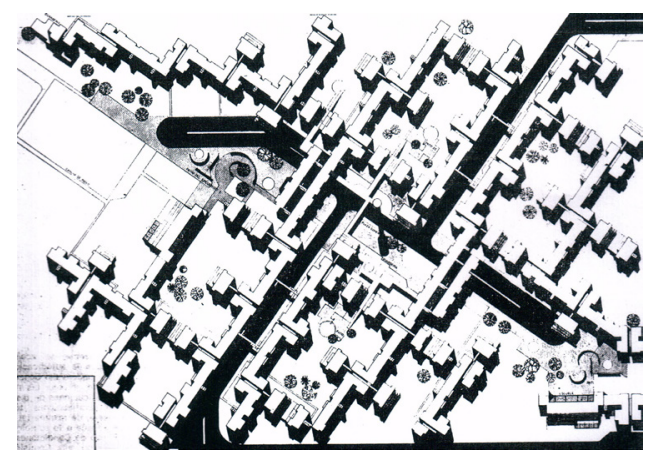

Figura 7.

STAFF. Proyecto urbano Florencio Varela. Planta de conjunto.
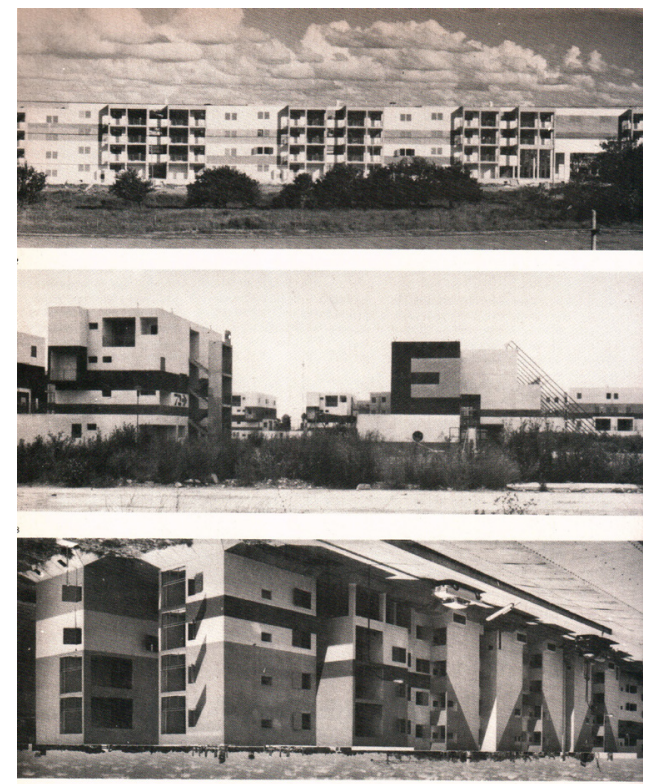

Figura 8.

STAFF. Proyecto urbano Florencio Varela. contemplaban variaciones en altura recreando el perfil casual de la ciudad, insertadas dentro de una grilla de rigurosa geometría, a la cual se incorporan transversalmente los bloques de baja altura.

Por último, en la urbanidad de Florencio Varela (1974), el estudio retoma la homogeneidad de la estructura horizontal e uniforme de bloques bajos de planta baja y tres pisos emplazados sobre la grilla. En la memoria descriptiva del proyecto, los autores definen un "partido": una arteria vehicular que entrelaza en diagonal el territorio, interceptando una espina circulatoria peatonal que forma cuatro áreas comunales definidas como "plazas de los encuentros", configuración que la urbanidad reelabora de experiencias precedentes.

\section{BREVES REFLEXIONES FINALES. LA PARADOJA DEL PARTIDO Y EL SISTEMA EN STAFF}

Como ha desarrollado Fernando Aliata, el "partido" como configuración apriorística en las elaboraciones proyectuales posibilitaba una síntesis formal impedida en la ortodoxia moderna, que paradójicamente, en la Argentina de los años sesenta pareció ensamblarse en armonía con los lineamientos de la Teoría de Sistemas:

¿Cómo se produce esta simbiosis entre ambas modalidades de proyectar? La arquitectura de sistemas ofrece la posibilidad de analizar 
el programa, desglosar todos sus segmentos, y recomponerlos en familias morfológicas o funcionales para luego construir un organismo donde cada una de las partes se relaciona de manera lógica. La estrategia de partido brinda, en cambio, la posibilidad de otorgar un aspecto definido al organismo sistémico que tiende con naturalidad hacia una infinitud amorfa

(Aliata; 2013: 58).

Así, y aun proviniendo de presuntos campos antagónicos para las decisiones sobre el proyecto, ambas estrategias no han colisionado sino que han podido complementarse durante ciertas producciones del desarrollismo argentino. En efecto, esa sinergia paradojal podría identificarse en la determinación de un patrón que conviviría con la articulación de sus partes según la lógica de los sistemas, que tiende naturalmente hacia la indeterminación formal. Ahora bien, ¿fue esta la estrategia adoptada por STAFF en sus producciones en materia de vivienda social, más allá de sus discursos y enfoques teóricos? El análisis de Waisman en Summa desestima la afinidad del equipo por los patrones formales predefinidos:

No parece sencillo compatibilizar la idea de una teoría de sistemas con un enfoque en el que priman la complejidad, la densidad, la ambigüedad. Para STAFF trabajar con sistemas significa construir la realidad a partir de una organización definida por medio de leyes, evitando una aproximación puramente visualista. Asimismo, critica JG, con razón a nuestro juicio, el concepto de tipología reducido a los aspectos formales, que suele manejarse usualmente en las tendencias recientes, y define a la tipología como un modelo resolutivo de combinaciones, que pueden abarcar los más diversos procedimientos -yuxtaposición, mezcla, simetría, etcétera-.

(Waisman; 1981: 27).

No obstante, partiendo de la construcción de Aliata y como hemos observado, es ciertamente reconocible ese encuentro en la contundente y reiterada impronta morfológica de las "tramas" en los proyectos urbanos de STAFF, surgidas mediante la articulación de unidades menores -los "bloques"- que luego logran reagruparse provocando posibles desplazamientos. En ese sentido, las elaboraciones discursivas más tardías de STAFF son reveladoras, y en cierto modo, contradicen sus teorías precedentes. En el número 169 de Summa destinado al periodo 1974-1981 de la oficina, sus integrantes señalaban, sobre sus lógicas proyectuales, que se propugnaba

Construir modelos más abstractos y tecnológicos con el solo fin de experimentar [...], tramas o mallas espaciales muy diversas y los tramos que resultan permiten 'sistemas de ensamble' y 'sistemas de permutación', imprevisibles. También aparatos o encadenamientos sistemáticos conducentes a intersecar mallas espaciales y 
funcionales (una ciudad, sistemas de servicio y circulación, etcétera)

(Goldemberg, Bielus, Wainstein; 1981: 88).

Goldemberg había referido que aquellas modelizaciones podrían resultar concretamente funcionales a los procesos proyectuales de la oficina:

Creemos que nuestros estudios previos de lógica e ingeniería de sistemas han tenido un peso decisivo en nuestro modo de pensar y en las 'ingeniosidades' técnicas, que aplicando métodos y leyes de sistematización, nos han permitido llegar a complicadas combinaciones, aparentemente irrealizables, o a sistematizar elementos de diseño que de otro modo hubiera sido imposible de incorporar a los proyectos

(Goldemberg; 1972: 88).

En esa dirección, es significativo que STAFF haya utilizado el concepto de "trama", con sutiles combinaciones de sus unidades morfológicas, en los cinco casos presentados, todos diseñados dentro del quinquenio 19701974, lo cual permitiría desarticular el discurso de un diseño urbano variable en función de la definición previa de su espacio y hábitat social. Más bien, encontramos aquí un patrón o modelo tipológico pasible de ser replicado, un "partido" según el estudio referenció en el conjunto Florencio Varela, cuya adopción probablemente haya sido alimentada por la multiplicación de los concursos a fines de los sesenta y principios de los setenta. Asimismo, si al menos en el discurso teórico, las alusiones a propiedades sistémicas apuntaban a un orden que parecía autogobernarse fuera de la dirección del profesional, en línea con las "megaestructuras ilimitadas" de Maki o los mat-building smithsonianos, la materialización de los proyectos de STAFF finalmente desnudó las limitaciones en cuanto a sus posibilidades crecederas reales, o al menos en relación a su adaptación a nuevas condiciones.

La experiencia trunca del desarrollismo en vivienda social quedó expuesta tardíamente a mediados de la década del setenta en Argentina, cuando la irrupción de la dictadura militar desarticuló los planes y programas habitacionales. El debilitamiento de la inversión del Estado significó asimismo la agonía de la experiencia formal de la "ciudad extensa" en los suburbios bonaerenses, simbiosis particular de las estrategias de partido y sistemas como solución a los grandes emprendimientos, alentada por STAFF y acompañada ocasionalmente por otras oficinas, como Aftalión, Bischof, Egozcue y Vidal ${ }^{9}$. Más no se trató de un movimiento aislado. En 1976 Reyner Banham publicaba Megaestructuras. Futuro urbano del pasado reciente, donde anunciaba el ocaso del fenómeno y la utopía sobre la construcción de proyectos urbanos de escala masiva. Allí indicaba que la instancia de mayor valoración de la efímera y potente actividad

9 Ver Conjunto Habitacional La Matanza. (1984). Revista Summa (197), 54-55. 

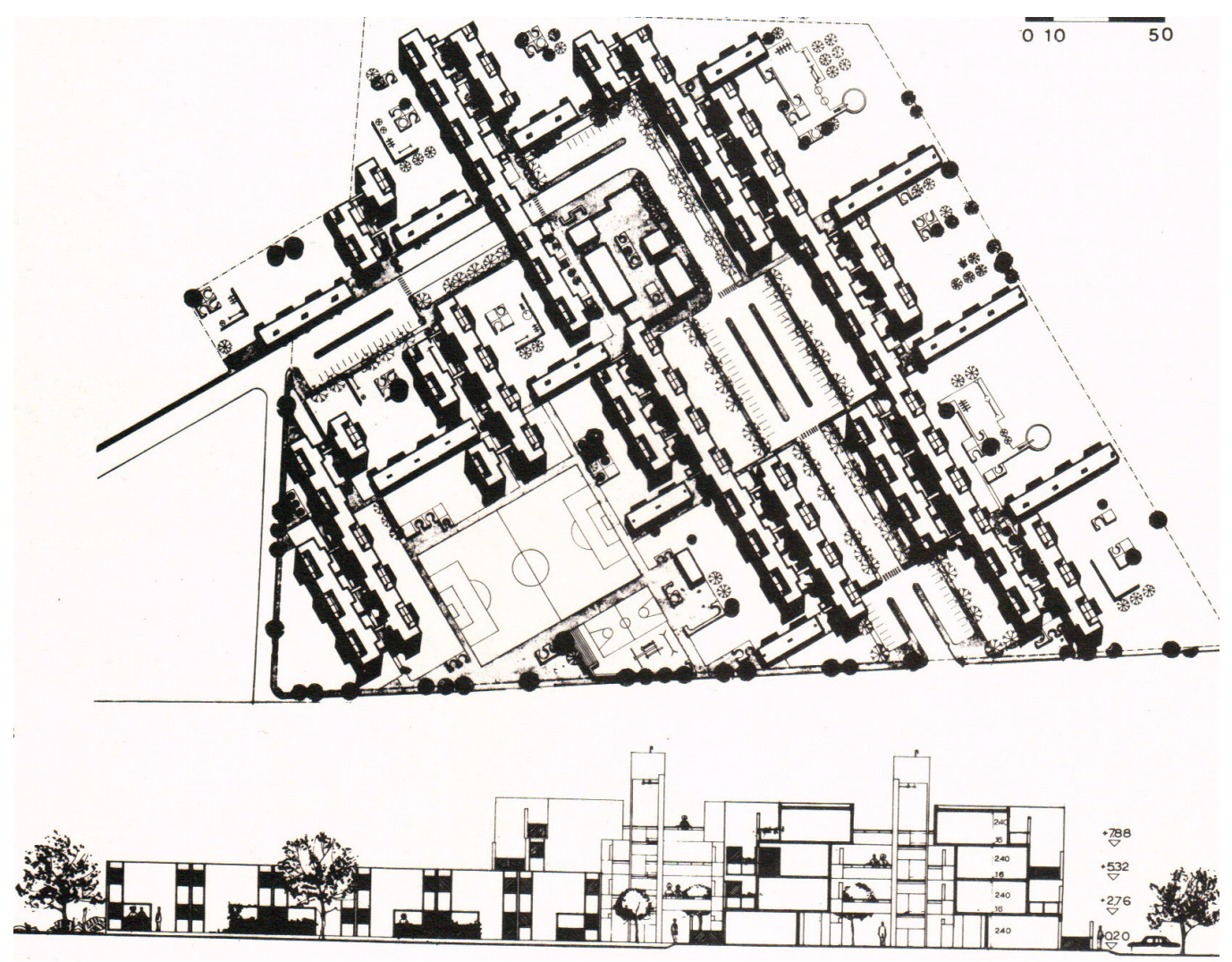

Figura 9.

Aftalión, Bischof, Egozcue, Vidal. Proyecto urbano La Matanza. Planta de conjunto y corte vista.

de las megaformas se situaría a mediados de

la década anterior, retrocediendo a 1964 -en

sincronía a la creación de STAFF- para señalar

el "annus mirabilis de las ideas y los proyectos"

(Banham; 2001: 70). 


\section{BIBLIOGRAFÍA}

ALIATA, F. (2013). Estrategias proyectuales. Los géneros del proyecto moderno. Buenos Aires: SCA.

BANHAM, R. (2001). Megaestructuras. Futuro urbano del pasado reciente. Barcelona: GG.

CARDOSO, F., \& FALETTO, E. (2005). Dependencia y Desarrollo en América Latina. Buenos Aires: Siglo XXI Editores.

COLQUHOUN, A. (2005). La arquitectura moderna. Una historia desapasionada. Barcelona: GG.

DUNOWICZ, R. (2000). 90 Años de Vivienda Social en la Ciudad de Buenos Aires. Buenos Aires: Universidad de Buenos Aires.

FERNANDEZ, R. (1996). La Ilusión Proyectual: Una Historia de la Arquitectura Argentina, 1955-1995. Mar del Plata, Facultad de Arquitectura, Urbanismo y Diseño Industrial: Universidad Nacional Mar del Plata.

FUSCO, M., \& LOPEZ, M. (2013). Arquitectura de sistemas en la vivienda colectiva. Conjunto SEP1 en Córdoba. En C. SHMIDT, C. (comp), 2das Jornadas de Historia y cultura de la arquitectura y la ciudad. La "Teoría de Sistemas" en la transformación de la cultura urbana. (pp. 50-59) Buenos Aires: UTDT.

GOLDEMBERG, J. (1973). Historia de nosotros, en Suplementos Summa, (64/65), Ediciones Summa SACIFI.
GOLDEMBERG, J., BIELUS, A., \& WAINSTEIN, 0. (1981). Sistemas, en Revista Summa (169), 88-89.

LIERNUR, J., \& ALIATA, F., (comps). (2004). Diccionario de Arquitectura en la Argentina. Estilos, obras, biografías, instituciones, ciudades. Buenos Aires: AGEA.

LIERNUR, J., (2008) Arquitectura en la Argentina del siglo XX. La construcción de la modernidad. Buenos Aires: Fondo Nacional de las artes.

MAKI, F. (1964). Investigations in collective form. St. Louis: Washington University.

NOVICK, A. (2012). Proyectos urbanos y otras historias. Buenos Aires: Nobuko.

PREBISCH, R. (1964). Nueva política comercial para el desarrollo. México DF: Fondo de Cultura Económica.

RIGOTTI, A. (2013). Un lugar en la cartografía de las megaformas, en C. SHMIDT, C., \& MÜLLER, L. (comps). 2as Jornadas de Historia y Cultura de la Arquitectura y la Ciudad. La Teoría de Sistemas en la transformación de la cultura urbana. Arquitectura, ciudad y territorio entre el profesionalismo y la tecno-utopía (19501980). (pp. 168-181). Buenos Aires: Universidad Torcuato Di Tella.

WAISMAN, M. (1973) Hacer es la consigna. Suplementos Summa (64/65). 


\section{REFERENCIA IMÁGENES}

WAISMAN, M. (1981). La ambigüedad controlada. Summa, (169), 26-29.

YUJNOVSKY, O. (1984). Claves Políticas Del Problema Habitacional Argentino, 1955-1981. Buenos Aires: Grupo Editor Latinoamericano.
Figura 01. MAKI, F. (1964). Investigations in coIlective form. St Louis, Washington University.

Figura 02. Revista Summa No. 64/65, Ediciones Summa SACIFI, noviembre de 1972.

Figura 03. Revista Summa No. 64/65, Ediciones Summa SACIFI, noviembre de 1972.

Figura 04. Revista Summa No. 64/65, Ediciones Summa SACIFI, noviembre de 1972.

Figura 05. Revista Summa No. 64/65, Ediciones Summa SACIFI, noviembre de 1972.

Figura 06. Revista Summa No. 64/65, Ediciones Summa SACIFI, noviembre de 1972.

Figura 07. Revista Summa No. 71, Ediciones Summa SACIFI, enero de 1974.

Figura 08. Revista Summa No. 71, Ediciones Summa SACIFI, enero de 1974.

Figura 09. Revista Summa No. 197, Ediciones Summa SACIFI, marzo de 1984. 